\title{
Mechanochemical Activation of Carboxy Methyl Cellulose and Its Thermoplastic Polyvinyl Alcohol/Starch Biocomposites with Enhanced Physicochemical Properties
}

\author{
Mohammad Taghi Taghizadeh ${ }^{1}$, Narges Sabouri ${ }^{1, *}$, Babak Ghanbarzadeh ${ }^{2}$ \\ ${ }^{1}$ Department of Physical chemistry, Faculty of Chemistry, University of Tabriz, P.O. Box 51666-16471, Tabriz, Iran \\ ${ }^{2}$ Department of Food Science and Technology, Faculty of Agriculture, University of Tabriz, Tabriz, Iran \\ Corresponding Author: narges.sabouri60@gmail.com
}

Copyright (C) 2013 Horizon Research Publishing All rights reserved.

\begin{abstract}
Polyvinyl alcohol (PVA) / starch (S) /Carboxy methyl cellulose (CMC) composite films were prepared from PVA, three different loading of CMC and soluble starch aqueous suspensions by casting method in the presence of plasticize containing glycerol. The effects of the CMC addition on the some physical properties of the resulted blend films were investigated. Tensile tests demonstrated positive results from mechanochemical treatment. With the addition of $20 \% \mathrm{CMC}$ was an increase in the tensile strength and percentage elongation at break. The thermal properties of polyvinyl alcohol (PVA)/Starch(S)/Carboxymethyl cellulose (CMC) blends were investigated by thermogravimetry (TGA) and derivative thermogravimetry (DTG). At least four degradation distinct stages were identified in the PVA/S/CMC blends by means of using TGA, being assigned to the mass loss due to the plasticizer leaching, and to the degradation of the starch, CMC and PVA fractions. The thermal stability of $\mathrm{PVA} / \mathrm{S} / \mathrm{CMC}$ blends is higher than that of PVA/S suggesting that the addition of CMC improved the thermal stability of PVA/S blend. The SEM (Scanning electron microscopy) indicates morphological structure of the polyvinyl alcohol/starch films in the different percent of CMC.
\end{abstract}

Keywords Polyvinyl Alcohol, Carboxy Methyl Cellulose, Biocomposites, Physical Properties, Thermogravimetry

\section{Introduction}

The severe environmental problems, including the increasing difficulties of waste disposal and the deepening threat of global warming (due to carbon dioxide release during incineration) caused by the nonbiodegradablility of a number of polymers (used in packaging and agriculture field) have raised concerns all over the world[1]. In order to solve the problems generated by plastic waste, many efforts have been done to obtain an environmental friendly material. Most of the researches are focused on substitution of the petro-based plastics by biodegradable materials with similar properties and low in cost [2-4]. Among the natural polymers, starch has been considered as one of the most promising candidates for this regard because of its attractive combination of price, abundance and thermoplastic behavior, in addition to biodegradability. The main disadvantage of biodegradable starch-based films is their hydrophilic character, which leads to low stability when these materials are submitted to different environmental conditions [5]. In addition, starch-based materials have poor mechanical properties and particularly poor elongation at ambient conditions. Thus, the incorporation of a plasticizer is required to overcome the brittleness of these materials. Plasticizers reduced intermolecular forces and increase the mobility of polymer chains, decreasing the glass transition temprature and increasing permeability [6]. One approach to improve the functional properties of starch films is to blend starch with other polymers (natural and synthetic). Biodegradable starch-based plastics such as starch/cellulose and starch/PVA have recently been investigated for their great potential marketability in agricultural foils, garbage and composting bags, and food packaging, in the fast food industry, and in biomedical fields [7-10]. PVA is a versatile polymer with many industrial applications, and it may be the only synthesized polymer whose backbone is mainly composed of C-C bonds that is absolutely biodegradable. PVA is the most readily biodegradable of vinyl polymers. It is readily degraded in wastewater activated sludge. The microbial degradation of PVA has been studied, as well as its enzymatic degradation by secondary alcohol peroxidases isolated from soil bacteria of pseudomonas strain. The excellent chemical resistance, optical and physical properties of PVA resins, has resulted in its broad industrial uses [11-13]. Carboxy methyl cellulose is cellulose ether forms excellent films. Because of its polymeric structure and high molecular weight, it is capable to use as filler in 
biocomposite films production. Carboxy methyl cellulose is able to improve the mechanical and barrier properties of starch-based films [14]. PVA, carboxy methyl cellulose and starch are polar polymers; thus a composite of PVA, carboxy methyl cellulose and starch is likely to produce a material having excellent mechanical properties [15]. This study reports on the effect of carboxy methyl cellulose content, on the properties of PVA/starch films, such as mechanical, thermal and morphological parameters. These studies were carried out to assess their potential uses as packaging films.

\section{Experimental}

\subsection{Materials}

Starch (ST) was provided by Merck company, and polyvinyl alcohol (PVA) with $\mathrm{Mn}=72000$ and glycerol $(\mathrm{Mn}=$ 92/10, 78\% purity) purchased from Merck company. Carboxymethyl cellulose sodium salt, with an average molecular weight of $\mathrm{Mn}=295225$ was purchased from Fluka company.

\subsection{Methods}

\subsubsection{Preparation of Films}

Films were obtained by the casting method [16]. First, PVA $(2.5 \mathrm{~g})$ was solubilized in $50 \mathrm{ml}$ of distilled water at $75^{\circ} \mathrm{C}$ for $15 \mathrm{~min}$ and starch $(2.5,2,1.5 \mathrm{~g})$ was mixed $\left(25^{\circ} \mathrm{C}\right.$ for $10 \mathrm{~min})$ with distilled water $(15 \mathrm{ml})$ and glycerol $(40$ $\mathrm{ml} / 100 \mathrm{~g}$ starch) then added to $20 \mathrm{ml}$ of boiling water to obtain a clear solution. Carboxy methyl cellulose $(0,0.5,1 \mathrm{~g})$ was solubilized in $75 \mathrm{ml}$ of distilled water at $75^{\circ} \mathrm{C}$ for $15 \mathrm{~min}$. Then, PVA, starch and CMC solutions were mixed together and stirred with using a magnetic bar at $75^{\circ} \mathrm{C}$ for 90 min with a reflux condenser. Then, about $70 \mathrm{ml}$ of the sample was poured into a Teflon casting tray and then dried at $60^{\circ} \mathrm{C}$ in oven to cast the films. The thickness of the films was $0.08 \pm 0.01 \mathrm{~mm}$. The thickness of the films measured with an Alton M820-25 hand-held micrometer having a sensitivity of $0.01 \mathrm{~mm}$.

\subsection{Solubility in Water}

Solubility in water was defined as the percentage of the dry matter of film which is solubilized after $24 \mathrm{~h}$ immersion in water [17].

Film specimens were kept in a desiccator containing dry calcium sulphate till they reached constant weight. Afterward, about $500 \mathrm{mg}$ of each film were immersed in beakers containing $50 \mathrm{ml}$ of distilled water at $23^{\circ} \mathrm{C}$ for $24 \mathrm{~h}$ with periodical gentle manual agitation. The Films were removed from the water and were placed back in the desiccator until they reached a constant weight to obtain the final dry weight of the film. The percentage of the total soluble matter (\%TSM) of the films was calculated using the following equation:

$\% \mathrm{TSM}=[($ initial dry $\mathrm{Wt}$-final dry $\mathrm{Wt}) /$ initial dry $\mathrm{Wt}]$

$$
\times \text { 100.(1) }
$$

TSM tests for each type of film were carried out in three replicates.

\subsection{Swelling Studies}

The extent of swelling was determined by a conventional gravimetric procedure [18]. In brief; a preweighed dried piece of a blend sample $(0.1 \mathrm{~g})$ was immersed in distilled water, and allowed to swell. By recording the weights of the swollen blends at desired time intervals, it was possible to monitor the extent of swelling. The swelling process was expressed in terms of the swelling ratio, as follows:

Swelling ratio $(\mathrm{SR})=$ Weight of swollen blend/ Weight of dry blend (2)

\subsection{Mechanical Properties}

Ultimate tensile strength (UTS) and strain to break (SB) of the films were determined at $21^{\circ} \mathrm{C} \pm 1^{\circ} \mathrm{C}$ using a tensile tester (Zwick/Roell model FR010, Germany) according to ASTM standard method D882-91 [19]. Three dumbbelly forms films $(8 \mathrm{~cm} \times 0.5 \mathrm{~cm})$ were cut from each of samples and were mounted between the grips of the machine. The initial grip separation and cross-head speed were set to $50 \mathrm{~mm}$ and 5 $\mathrm{mm} / \mathrm{min}$, respectively.

\subsection{Thermal Properties}

Thermogravimetry was carried out using a Perkin Elmer pyris diamond TG-DTA instrument at heating rate $\left(10{ }^{\circ} \mathrm{C}\right.$ min-1) under inert atmosphere (nitrogen environment) in order to avoid thermoxidative degradation. Temperature programs for dynamic tests were run from 0 to $500^{\circ} \mathrm{C}$.

\subsection{Scanning Electronic Microscopy (SEM)}

The morphology of the surface of the films was investigated using a scanning electronic microscope of XL30 type (Netherland). The films were covered with pure metallic $\mathrm{Au}$. The laying down of $\mathrm{Au}$ was carried out using evaporation of the metal under a high vacuum, to give a thickness of around $100^{\circ} \mathrm{A}$.

\section{Results and Discussion}

\subsection{Solubility in Water}

The water solubility of the PVA/S/CMC films as a function of CMC content is shown in Fig. 1.

Addition of $\mathrm{CMC}$, in all concentrations, increased the water solubility of films. The \%TSM was $27.41 \%$ for the samples without CMC, which increased to $33.77 \%, 43.71 \%$ and $46.27 \%$ for the films containing 5, 10 and $20 \% \mathrm{~W} / \mathrm{W}$ 
CMC, respectively. This is in agreement with [20] that investigated the effect of CMC on the solubility in water of the thermoplastic starch/CMC and reported that when filler content increased, the solubility in water values increased gradually. The observed results may be explained by the fact that an increased CMC content in the blend renders the network more hydrophilic and henceforth, the degree of water sorption increases, which, in turn, increases the solubility in water.

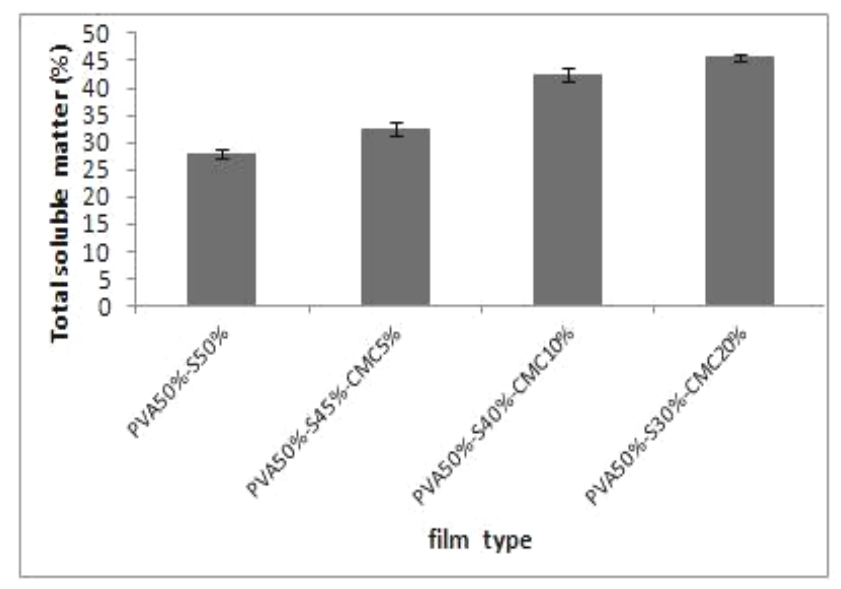

Figure 1. Water solubility of the PVA/S/CMC films as a function of CMC content

\subsection{Swelling Studies}

The swelling ratio of the PVA/S/CMC films as a function of CMC content is shown in table 1 .

Addition of CMC, in all concentrations, increased the SR of PVA/S/CMC films. This is in agreement with [20] that investigated the effect of $\mathrm{CMC}$ on the swelling ratio of the thermoplastic starch/CMC and reported that when filler content increased, the swelling ratio values increased gradually. Carboxymethyl cellulose (CMC), being a modified natural water-soluble polymer, contains hydroxy and carboxyl groups which impart hydrophilicity to the molecule. When the weight fraction of CMC is increased in the reaction mixture of the blend, the swelling ratio is found to increase substantially. The observed results may be explained by the fact that an increased CMC content in the blend renders the network more hydrophilic and henceforth, the degree of water sorption increases, which, in turn, increases the swelling ratio. Another plausible explanation rests upon the possibility that as the content of CMC increases in the blend matrix, there may be an increase in the mutual repulsion between the carboxylate groups of the CMC molecules, which relaxes the network chains of the blend and widens the mesh sizes of the blend. This ultimately results in enhanced swelling of the system.

\subsection{Mechanical Properties}

Figs. 2,3 show the relationships between $\mathrm{CMC}$ content and the tensile properties of the PVA/S/CMC films. The UTS and SB as the function of CMC concentration are shown in Figs. 2 and 3, respectively.

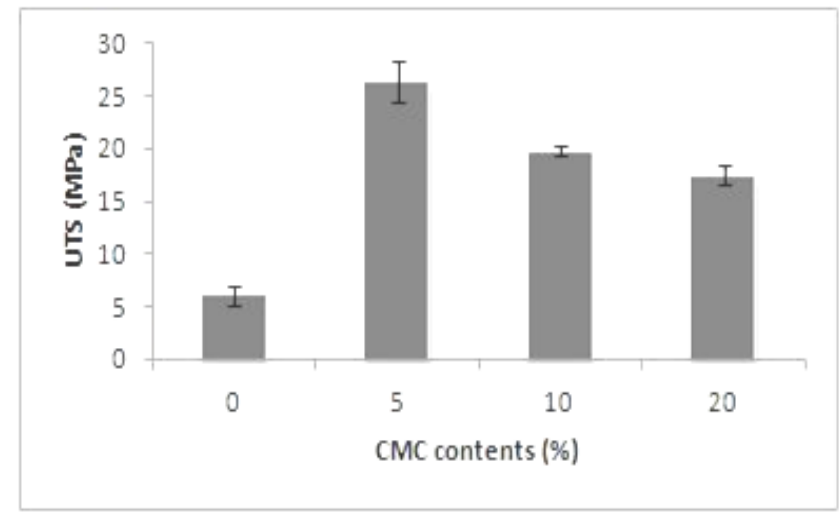

Figure 2.The ultimate tensile strength (UTS) of the PVA/S/CMC films as a function of CMC content.

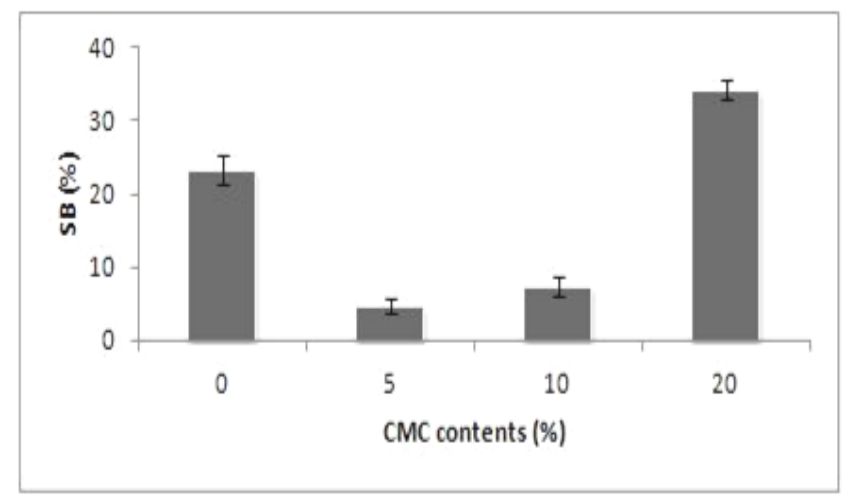

Figure 3.The strain to break (SB) of the $\mathrm{PVA} / \mathrm{S} / \mathrm{CMC}$ films as a function of CMC content

It was observed an important increase of fourfold in the UTS when $5 \% \mathrm{~W} / \mathrm{W}$ of CMC was added to the PVA/starch, but with increasing CMC concentration from $5 \%$ to $20 \%$, the UTS decreased from 27.88 MPa to $18.36 \mathrm{MPa}$. Therefore, with increasing $\mathrm{CMC}$ concentration from $0 \%$ to $20 \%$, the UTS increased significantly from $6.38 \mathrm{MPa}$ to $18.36 \mathrm{MPa}$. This was probably due to the interfacial interaction between the matrix and filler due to the chemical similarity (polysaccharide structure) of starch and CMC. It was interesting that with increasing $\mathrm{CMC}$ concentration (from $0 \%$ to $20 \%$ ), the UTS increased significantly. It was observed an important decrease of sixfold in the SB when $5 \% \mathrm{~W} / \mathrm{W}$ of $\mathrm{CMC}$ was added to the PVA/starch, but with increasing $\mathrm{CMC}$ concentration from $5 \%$ to $20 \%$, the SB increased from $4.03 \%$ to $35.56 \%$. This is in agreement with [14] who reported a significant improvement mechanical property of starch films is achieved by adding relatively small amounts of CMC (till 10\%). Therefore, with increasing CMC concentration from $0 \%$ to $20 \%$, the SB increased significantly from $23.86 \%$ to $35.56 \%$. It seems CMC could improve the films strength without depressing effect on flexibility.

\subsection{Thermal Properties}

The TGA and DTG curves for PVA50/S50 and PVA50/S30/CMC20 blends at heating rate $10^{\circ} \mathrm{C} / \mathrm{min}$ are shown in Figures 4 and 5 respectively. 


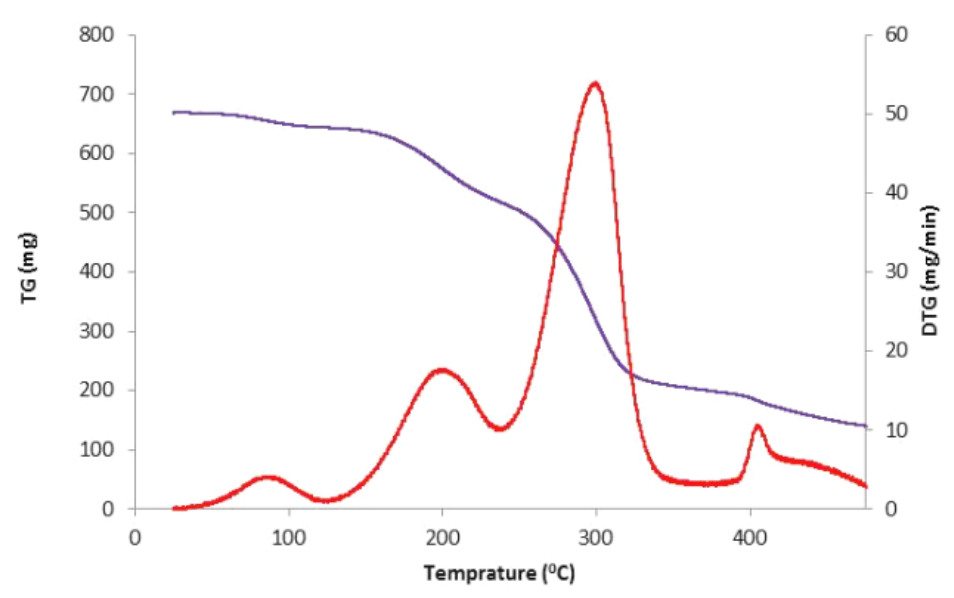

Figure 4. The TGA and DTG curves for PVA50/S50 blend at heating rate $10^{\circ} \mathrm{C} / \mathrm{min}$

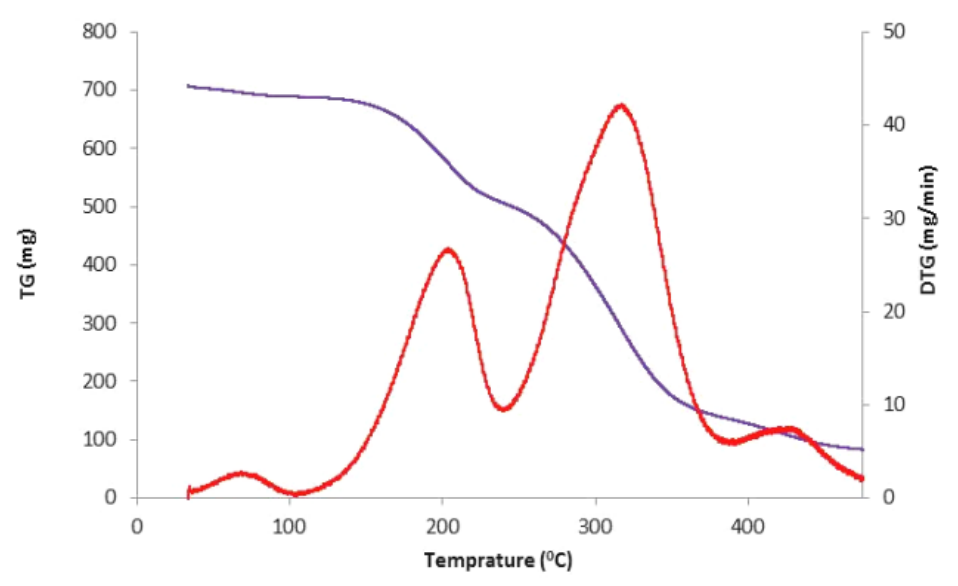

Figure 5. The TGA and DTG curves for PVA50/S30/CMC20 blends at heating rate $10^{\circ} \mathrm{C} / \mathrm{min}$

Table 2. The peaks, positions of the mass loss of all these three processes (exception first peak) in all the studied blends at heating rate $10^{\circ} \mathrm{C} / \mathrm{min}$

\begin{tabular}{|c|c|c|c|}
\hline Sample & PVA50-S50 & PVA50-S40-CMC10 & PVA50-S30-CMC20 \\
\hline $10^{0} \mathrm{C} /$ min, $\operatorname{second} \operatorname{peak}\left({ }^{0} \mathrm{C}\right)$ & 202 & 202 & 203 \\
\hline Third peak $\left({ }^{0} \mathrm{C}\right)$ & 229 & 304 & 316 \\
\hline Fourth peak $\left({ }^{\circ} \mathrm{C}\right)$ & 406 & 415 & 420 \\
\hline
\end{tabular}

It can be seen that both PVA/S and PVA/S/CMC blends exhibited a four-step degradation pattern. As samples contain a small quantity of water (water of free), the first stages of degradation (up to about $90^{\circ} \mathrm{C}$ ) represent the evaporation of the water of degraded components. The second stages of degradation (up to about $220^{\circ} \mathrm{C}$ ) represent the volatilization of the easily degraded components such as glycerol [21]. The major mass loss took place in the third step (from about 250 to $360^{\circ} \mathrm{C}$ ), and was followed by a further smaller mass loss in the fourth step (from about 380 to $440^{\circ} \mathrm{C}$ ). The third step of weight loss was predominantly the characteristic degradation of a polymer structure (water elimination of PVA, decomposition of Starch and decomposition of CMC) $[22,23]$. Further heating broke down the polymer backbone (cracking of PVA) [24,25]. The non-volatile residues of approximately $5-10 \mathrm{wt} \%$ were left for the studied samples. Affirmatively, the third step was the predominant degradation process.

The peaks, positions of the mass loss of all these three processes (exception first peak) in all the studied blends at the heating rate $10^{\circ} \mathrm{C}$ are shown in table 2 . The thermal stability of PVA/S/CMC blends is higher than that of PVA/S suggesting that the addition of CMC improved the thermal stability of PVA/S blend.

\subsection{Scanning Electronic Microscopy (SEM)}

Fig. 6 shows the morphology of PVA/S/CMC films with different contents of starch and CMC. The addition of CMC significantly changes the morphology of $\mathrm{PVA} / \mathrm{S} / \mathrm{CMC}$ composite. Blends PVA/starch and PVA/S/CMC had a 
uniform morphology, with no evidence of phase separation. Homogeneous distributions of the CMC in the PVA/S/CMC matrix were observed in all composite films, implying good adhesion between fillers and matrix. This is attributed to the good compatibility resulting from the chemical similarities between starch and carboxymethyl cellulose and the hydrogen bonding interactions existing in the interface between PVA, starch and CMC. Such an event and uniform distribution of the fillers in the matrix could play an important role in improving the mechanical performance of the resulting composite films.
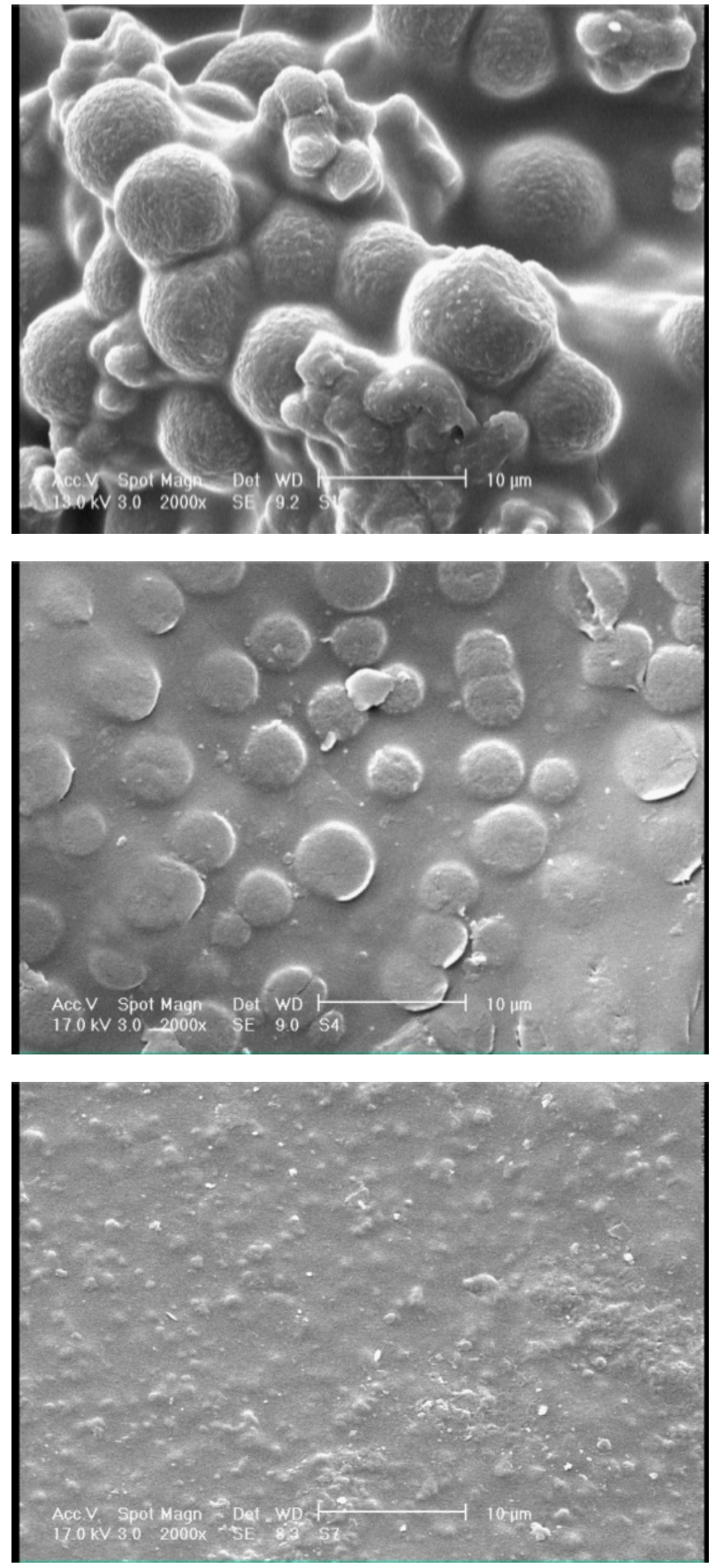

Figure 6. SEM micrograph of the composites of PVA50\%/S50\% (a) PVA $50 \% / \mathrm{S} 40 \% / \mathrm{CMC} 10 \%$ (b) and PVA $50 \% / \mathrm{S} 30 \% / \mathrm{CMC} 20 \%$ (c)

\section{Conclusions}

The present study shows the role of CMC on the physicmechanical properties of $\mathrm{PVA} / \mathrm{starch}$ films. The addition of $\mathrm{CMC}$ to $\mathrm{PVA} /$ starch blends improved the mechanical properties of the resulted starch based composites. CMC ( $20 \% \mathrm{~W} / \mathrm{W}$ film) could increase the UTS and SB of starch based composite films by more than $35 \%$ and $67 \%$ compared to the PVA/starch film respectively. Solubility of the films increased from $27.14 \%$ to $46.27 \%$. At least four degradation distinct stages were identified in the $\mathrm{PVA} / \mathrm{S} / \mathrm{CMC}$ blends by means of using TGA, being assigned to the mass loss due to the plasticizer leaching, and to the degradation of the starch, CMC and PVA fractions. The thermal stability of PVA/S/CMC blends is higher than that of PVA/S suggesting that the addition of CMC improved the thermal stability of PVA/S blend. In addition, by increasing of CMC content, outward properties of the composite films improved appreciably. With considering these results, it seems that the PVA/S/CMC biocomposit films show better physicomechanical properties than PVA/starch films and can be potentially replaced of PVA/starch films.

\section{Acknowledgements}

We are grateful to University of Tabriz Research Council for the financial support of this research.

\section{REFERENCES}

[1] GishaeLuckachan C.K.S. J. Polym. Environ. 2011, 19,637.

[2] Mali, S.; Sakanaka, L.S.; Yamashita, F.; Grossmann, M.V.E. J. Carbohyd. Polym. 2005, 60, 283.

[3] Mariniello, L., Giosafatto, C.V.L., Moschetti, G., Aponte, M., Masi, P., Sorrentino, A., Porta, R. J. Biomacromol. 2007, 8, 3008 .

[4] Larotonda, F.D.S.; Matsui, K.N.; Sobral, P.J.A.; Laurindo, J.B. J. Food Eng. 2005, 71, 394.

[5] Muller, C. M. O., Yamashita, F., \&Laurindo, J. B., J. Carbohyd. Polym. 2007, 10, 1016.

[6] Averous, L.; Boquillon, N. J. Carbohyd. Polym. 2004, 56, 111.

[7] Funke, U.; Bergthaller, W.; Lindhauer, M. G. J. Polym. Degrad. Stab. 1998, 59, 293.

[8] Lourdin, D.; Valle, G. D.; Colonna, P. J. Carbohyd. Polym. 1995, 27, 261.

[9] Van Soest, J. J. G.; Benes, K.; De Wit, D. J. Polym. 1996, 37, 3543 .

[10] Briassoulis, D. J. Polym. the Environ. 2004, 12, 65.

[11] Suzuki, T. J. Polym. Sympos. 1979, 35, 431.

[12] Watanabe, Y.; Morita, M.; Hamade, N.; Tsujisake, Y. J. 
Agricul. Biolog. Chem. 1975, 39, 2447.

[13] Morita, M.; and Watanabe, Y. J. Agricul. Biolog. Chem. 1977, $41,1535$.

[14] Ma, X.; Chang, P.R.; Yu, J. J. Carbohyd. Polym. 2008, 72, 369.

[15] SiddaramaiahNagarahalli, R. T.; Ravi, P.; Kumar, K. P.; \&jagadeesh, K. S. J. Polym. Mat. 1999, 16(3), 233.

[16] Yoon, S. D.; Chough, S. H.; Park, H. R. J. Appl. Polym. Sci. 2006, 100, 2554.

[17] Gontard, N.; Duchez, C.; Cuq, B.; \&Guilbert, S. J. Food Sci. Techno. 1994, 29, 39.

[18] Bajpai, A K.; Bajpai, J.; and Shukla, S. J. React. Func. Polym. 2001, 50, 9.
[19] ASTM, Standard test methods for tensile properties of thin plastic sheeting, D882-91. Annual book of ASTM. Philadelphia, PA: American Society for Testing and Materials, 1996.

[20] Bajpai, A K., J. Polym. Intern. 2005, 54, 1524.

[21] Vega, D.; Villar, M A.; Failla, M D.; Valles, E M. J. Polym. Bull, 1996, 37, 229.

[22] Holland, B.J.; Hay, J.N. J. polym, 2001, 42, 6775.

[23] Alvarez, V A.; Vazquez, A. J. Polym. Degrad. Stab. 2004, 84, 13.

[24] Thomas, P S.; Guerbois, J P.; Russell, G F and Briscoe, B J. J. Therm. Analys. and Cal. 2001,64, 501.

[25] ZHOU, X Y.; JIA, D M.; CUI, Y F AND XIE, D. J. REINFO. PLAST. AND COMPOS. 2009, 28( 22), 2771. 